\title{
Prevalence of dental caries and associated factors among primary school children: a population-based cross-sectional study in Riyadh, Saudi Arabia
}

Yazeed Abdullah Alhabdan ${ }^{1,2,3}$, Abdulhameed Ghassan Albeshr ${ }^{1,2,3}$, Nagarajkumar Yenugadhati ${ }^{1,2^{*}}$ (D) and Hoda Jradi ${ }^{1,2}$

\begin{abstract}
Background: Dental caries is a preventable childhood disease, but public health efforts are hampered due to limited information on associated factors in vulnerable populations. Our study was aimed at estimating the prevalence of dental caries and identifying key associated factors in four major risk domains, including socioeconomic factors, child oral health behavior and practices, child feeding practices, and dietary habits among primary school children in Saudi Arabia.
\end{abstract}

Methods: A cross-sectional study design was used to recruit 578 male Saudi primary school children, aged 6-8 years, from 12 primary schools in five different regions of Riyadh. Children were clinically screened to detect carious lesions in primary teeth according to World Health Organization's criteria. Structured self-administered questionnaire was used to collect information on social and individual factors from the parents. The odds ratios and $95 \%$ confidence intervals of associated factors for dental caries were computed using logistic regression models; key factors were identified by systematic selection process that accounted for multicollinearity and bias correction.

Results: Dental caries was prevalent among children (83\%, 95\% confidence interval 79.7-86.0\%). Individual factors, including irregular brushing, late adoption of brushing habit, consulting dentist for symptomatic treatment, lack of breast feeding, sleeping with a bottle in mouth, habit of snacking between meals, low consumption of fruits, and frequent consumption of soft drinks and flavored milk, were predominantly associated with dental caries in children, instead of socioeconomic factors ( $p<0.05$, adjusted $R$-square $80 \%$ ).

Conclusion: Dental caries were prevalent in school children, and individual factors were predominantly associated with the disease.

Keywords: Dental caries, Primary teeth, Prevalence, Associated factors, Children

\footnotetext{
* Correspondence: nagarajkumar.yenugadhati@gmail.com

${ }^{1}$ King Abdullah International Medical Research Center (KAIMRC), Riyadh,

Saudi Arabia

2Department of Epidemiology and Biostatistics, College of Public Health and

Health Informatics, King Saud bin Abdulaziz University for Health Sciences,

Mail Code 2350, P.O. Box 22490, Riyadh 11426, Saudi Arabia

Full list of author information is available at the end of the article
}

(c) The Author(s). 2018 Open Access This article is distributed under the terms of the Creative Commons Attribution 4.0 International License (http://creativecommons.org/licenses/by/4.0/), which permits unrestricted use, distribution, and reproduction in any medium, provided you give appropriate credit to the original author(s) and the source, provide a link to the Creative Commons license, and indicate if changes were made. The Creative Commons Public Domain Dedication waiver (http://creativecommons.org/publicdomain/zero/1.0/) applies to the data made available in this article, unless otherwise stated. 


\section{Introduction}

Dental caries is a major oral health problem affecting 2.43 billion people (35.3\% of the population) worldwide in the year 2010 [1]. A high burden of dental caries was evident among children in Saudi Arabia with an estimated prevalence of approximately 80\% [2]; other high-risk areas include Latin America, Middle East, and South Asia [3]. The World Health Organization (WHO) emphasizes the need to reduce global burden of dental caries in attaining optimal health. Consequently, in the year 2003, WHO and Fédération Dentaire Internationale (FDI) World Dental Federation set global goals for oral health in 2020 to guide planners and policy makers to improve the status of oral health in their populations [4]. Unfortunately, knowledge gaps with respect to the availability of baseline data on oral health and population-specific key modifiable factors of dental caries restrict the ability of many developing nations and semi-developed countries, including Saudi Arabia to attain the goals set by WHO. In addition, competing interests in health care funding warrant prioritizing the associated factors to better direct public health mitigation efforts.

Although factors, such as occupational status, family income, and level of education of parents [5-9] that affect the socioeconomic status of populace, have been associated with dental caries, their relative impact on dental caries compared to individual factors is unclear. Moreover, modification of socioeconomic factors requires time-consuming macro level changes. In contrast, individual factors, such as child oral health behaviors, child feeding practices, and dietary habits that play a role in cariogenesis, could be targeted for modification by directing the limited resources to primary school children. Prior evidence illustrates the importance of adopting good oral health behaviors such as regular brushing of teeth, using mouthwash, and flossing teeth in reducing the disease burden and attaining optimal oral health [10]. Similarly, the role of sugary foods (e.g., candies) in cariogenesis was also well established [11]. However, the relative significance of aforementioned oral behavioral factors on cariogenesis compared to other host factors could vary significantly in different populations owing to cultural and behavioral practices.

In our globalized world, constant migration of individuals and transfer of certain behaviors or practices (e.g., favoring flavored milk over plain milk among children) [12] is the prevailing norm. Therefore, the knowledge of associated factors for dental caries in Saudi children not only benefit Saudi populace but also international organizations such as WHO and health authorities in directing the mitigation efforts at vulnerable populations (e.g., children).
This study aimed at estimating the prevalence of dental caries in primary teeth and identifying key associated factors in 6-8-year-old school children in Riyadh city of Saudi Arabia would contribute towards the knowledge of dental caries by enriching the baseline data and determining population-specific risk factors of such a highly prevalent and preventable condition. Our analysis is the first in Saudi Arabia to comprehensively evaluate and prioritize factors encompassing all four major risk domains for dental caries, including parental socioeconomic status, children oral health behavior and practices, child feeding practices, and dietary habits. In addition, the relative importance of individual factors (over socioeconomic factors) as determinants of dental caries was assessed using extensive modelling techniques.

\section{Methods}

A population-based cross-sectional study design was employed to determine the burden of dental caries in primary teeth and key associated factors among 68 -year-old male primary school children recruited from 12 government primary schools for boys located in 5 geographical regions (southern, northern, eastern, western and central) in Riyadh city, Saudi Arabia. The study included only Saudi nationals, whose parents were able to fill the self-administered questionnaire and provide informed consent for their child's dental examination at school. Non-Saudi children or children with non-Saudi care givers or parents were excluded. This study was conducted in the year 2015 between September 1 and November 30.

\section{Sample size}

Sample size was calculated using single proportion formula based on $95 \%$ confidence level, expected prevalence of $80 \%$ [2], precision of 0.05 , and design effect of 2 . The recommended sample size was 492 children with one of their parents as a single unit.

We anticipated low response rate owing to the outbreak of Middle East respiratory syndrome-corona virus (MERS-cov) in Riyadh city during the study period. Therefore, a total of 1130 questionnaires were distributed to parents and we received 578 completed questionnaires at a response rate of $51 \%$ from 12 out of 15 schools considered for recruitment among 513 government primary schools for boys in Riyadh region.

\section{Sampling technique}

Our study sample was obtained by a multistage random sampling technique. Briefly, up to three primary schools in Riyadh were randomly selected from each of the five geographical locations in Riyadh city based on the list of primary schools obtained from the Ministry of Education. A maximum of 80 students were randomly selected 
from each of these schools. Each of the five regions in Riyadh city contributed a fifth of the total study sample.

\section{Screening for dental caries}

Children underwent a simple dental examination based on the World Health Organization diagnostic criteria for oral health surveys [13]. The basic oral assessment of every child was performed by a single, well-trained professional dentist by seating each subject on a chair in a good day light using mouth mirror and dental probes. This simple oral examination poses no harm to children. The intra-examiner reliability was good based on re-examination of 30 children prior to the study (kappa value $=0.98)$. Caries status in the crown of primary teeth was assessed using decayed (d), missing (m), and filled (f) teeth $(\mathrm{dmft})$ index [2, 13]; teeth missing $(\mathrm{m})$ or filled (f) contributed to the overall dmft score only if they were missing or filled because of caries. A dmft score above null indicates the presence of caries, whereas a null score indicates the absence of caries [13].

\section{Parental questionnaire}

A structured self-administered parental questionnaire was developed by relying on previous studies [13-20] and accounting for cultural sensitivities of the study population. The questionnaire was translated into Arabic and then back to English to ensure accuracy. Face validity, feasibility, and construct validity of the questionnaire was established prior to study.

The questionnaire responses provided data on age of the child, demographic and socioeconomic factors such as father's education level, mother's education level, parental occupation as health care provider, monthly income of the family, region of residence, type of residence, and availability of medical insurance with dental coverage. Parents also provided information on oral health behavior and practices of children, such as frequency of brushing teeth with toothpaste in a day; age at which children started brushing; use of dental floss; use of mouthwash; frequency of fluoride application; recent visit to the dentist; habit of eating after brushing teeth in night; and child feeding practices, such as type of milk feeding practice (breast-fed only/children mixed-fed with both breast milk and powdered milk/powdered milk only), age of child when breast feeding was stopped, age of child when bottle feeding was stopped, child sleeping with bottle in mouth, number of meals per day, number of snack items consumed between meals, and snack time corresponding to main meals (ate snacks with main meals only/ate snacks in between main meals or with main meals). Dietary information included use of multivitamin supplementation (no/yes) and consumption of fresh fruits, fresh vegetables or salads, fast food, candy, potato chips, sweetened chewing gum, fresh juice, flavored juices, soft drinks, fresh milk, and flavored milk at least twice a week (no/yes).

Some of the original variable categories were combined to create meaningful new groups, and facilitate appropriate analyses. In particular, the 'frequency of brushing teeth' variable was classified in to 3 categories (children brushing less than once daily/once daily/two times or more daily.

\section{Statistical analysis}

All analyses of study data were performed using SAS software version 9.4 (SAS Institute Inc., Cary, NC, USA). Categorical variables were described as counts and percentages, whereas means and standard deviations (SD) were computed for continuous variables. The 95\% confidence intervals for proportions were constructed using Clopper-Pearson exact tests. The independence of characteristics of study sample by caries status (presence or absence) was assessed using Pearson's chi-squared test (or Fisher's exact tests for smaller samples) and $p$ values. Missing data were analyzed as a separate category (unknown or other) in corresponding variables.

The main associated factors for dental caries in our study were determined in three steps. In the first step, the association between each characteristic of study sample and the presence of dental caries was evaluated using univariate logistic regression analyses; all the variables that were significant at $p$ value less than or equal to 0.05 were selected for second step of analyses. In the second step, the associated factors for dental caries among each of the four broader determinants of health, including socioeconomic factors, child oral health behavior and practices, child feeding practices, and dietary factors, were identified based on four separate stepwise logistic regression analyses. Subsequently, the covariates that were significant $(p \leq 0.05)$ in each of the four analyses were selected for further analysis. In the final step, a stepwise multivariate logistic regression analysis was performed on covariates selected from step two and variable age group of the child (6 or 7 or 8 years) to determine key associated factors for dental caries. In addition, multicollinearity was assessed using collinearity indices, eigenvalues, and variable decomposition proportions for all the multivariate models. One of the highly collinear variables was removed giving precedence to children oral health behavior and practice covariates. In addition, Firth's bias correction was applied to the final multivariate model to address potential issues due to small sample size, and complete or quasi-complete separation.

The measures of association were reported as unadjusted odds ratios (uOR) and adjusted odds ratios (aOR) along with their corresponding 95\% confidence intervals $(95 \% \mathrm{CI})$. The discrimination, calibration and 
overall performance of the final multivariate model was assessed using concordance statistic, Hosmer and Lemeshow goodness-of-fit test, and adjusted Cox and Snell $R$-square, respectively. The performance of final model with and without socioeconomic factors was compared based on adjusted Cox and Snell $R$-square, which indicates the proportion of variation explained by the covariates in the model. Statistical analyses that yielded a $p$ value less than or equal to 0.05 were considered significant.

\section{Results}

A total of 578 primary school boys aged 6 to 8 years in Riyadh, Saudi Arabia, were analyzed in this study. The prevalence of dental caries in our sample was $83 \%$ (95\% CI $79.7-86.0 \%$ ). About $17 \%$ (95\% CI 14.0-20.3\%) of children had no carious lesions. The age-specific prevalence of dental caries among children aged 6,7 , and 8 years was 87.6\% (95\% CI 82.4-91.6\%), 72.9\% (95\% CI 65.9-79.1\%), and $88.4 \%$ (95\% CI $82.7-92.8 \%$ ), respectively. The mean age and dmft score in our sample was $6.92(\mathrm{SD} \pm 0.82)$ and 4.20 ( $\mathrm{SD} \pm 2.96)$, respectively.

Table 1 provides the frequencies, percentages, and differences (by caries status) for various characteristics of study population. A significant number of fathers (65.7\%, 95\% CI 61.7-69.6\%) and mothers (73.9\%, 95\% CI $70.1-77.4 \%$ ) did not attend a college or university, and their children experienced high prevalence of dental caries. Majority of the children came from low-income families (59.7\%, 95\% CI 55.6-63.7\%), and approximately $99 \%$ of them experienced dental caries. Most of the study subjects lived in rental homes, and $77 \%$ had no dental coverage in medical insurance. In general, the children had poor oral health behavior and practices as most of them started brushing at a late age ( 5 or more years) and brushed less than once daily (55\%) in any given week. The use of dental floss and mouthwash was negligible, and most of the children visited a dentist for symptomatic treatment. Although the practice of breast feeding is common, most of the children were weaned by the first year. The practice of mixed feeding was common in our sample; approximately $81 \%$ of mixed-fed children experienced dental caries compared to $93 \%$ of children that were exclusively fed with either breast milk or powdered milk. The practice of sleeping with a bottle in mouth and frequent consumption of sugary snacks between meals was also common. The consumption of fresh fruits and fresh juice was less prevalent in our sample.

The summary of variables selected during different steps of selection process is illustrated in Table 2. Barring few exceptions, almost all the factors were significantly associated with dental caries' experience in univariate analyses (step 1). In the ensuing step 2 multivariate analysis, a limited number of factors were associated with dental caries in each of the four risk domains with more concessions observed among dietary factors. In the final step of model selection, the highly collinear child feeding covariate (i.e., age of the child when breast feeding was stopped) was excluded to address multicollinearity. Our model selection process yielded 12 variables that were significant at $p<0.05$ for inclusion in the final model. Although association measures were not provided in Table 2 to avoid confusion, interested readers could find these details in Additional file 1.

The unadjusted and adjusted odds ratios along with their 95\% confidence intervals (based on Firth's bias correction) for the variables, representing all four risk domains, in the final model are reported in Table 3. It should be noted that factors representing low socioeconomic status, such as low level of maternal education, low family income, and lack of dental insurance, were associated with a minimum of fourfold increased dental caries experience. Child oral health practices, such as failure to brush teeth at least once a day, failure to start brushing on or before a child attained 2 years of age, and visiting dentist for symptomatic treatment, were associated with dental caries experience in children. Children habituated to sleeping with bottle in mouth experienced 4.4-fold higher dental caries compared to children not practicing this habit $(\mathrm{aOR}=4.4,95 \% \mathrm{CI}$ 1.4-13.4). In addition, lack of mixed feeding and consuming two or more sugary snack items between meals were predominantly associated with dental caries experience $(p<0.05)$. Dietary habits, such as less consumption of fresh fruits and frequent consumption of soft drinks and flavored milk, were significantly associated with dental caries with an odds ratio of 11.6, 5.3, and 7.7, respectively. The final model was well calibrated ( $p=0.7667$; Hosmer and Lemeshow goodness-of-fit test) with very high discriminatory power $(c$-statistic $=99 \%)$ and high overall performance (adjusted $R$-square of $88 \%$ ).

Subsequent exclusion of three variables representing socioeconomic status from the final model also resulted in a well-calibrated model $(p=0.3502$; Hosmer and Lemeshow goodness-of-fit test) with very high discriminatory power $(c$-statistic $=98 \%)$. However, a slight reduction in overall performance from 88 to $80 \%$ was noted, signifying the influence of individual or personal factors (represented in the remaining three risk domains) on dental caries experience in children; the overall performance of model with variables representing socioeconomic status was $59 \%$. In addition, the higher magnitude of adjusted odds ratios of individual factors (ranging from 4.4 to 38.4) compared to aORs of socioeconomic factors (ranging from 4.2 to 28.2) and the lower confidence limits that were consistently above 1.5 lend further support to the predominant 
Table 1 Distribution of various characteristics of study population and the relationship with caries status

\begin{tabular}{|c|c|c|c|c|}
\hline \multirow[t]{2}{*}{ Characteristic } & \multirow{2}{*}{$\begin{array}{l}\text { All subjects } \\
(n=578)\end{array}$} & \multicolumn{2}{|l|}{ Caries status } & \multirow[t]{2}{*}{$p$ value* } \\
\hline & & Yes $(n=480)$ & No $(n=98)$ & \\
\hline \multicolumn{5}{|l|}{ Age group } \\
\hline 6 years & 217 & $190(87.6)$ & $27(12.4)$ & \multirow[t]{3}{*}{$<0.0001$} \\
\hline 7 years & 188 & $137(72.9)$ & $51(27.1)$ & \\
\hline 8 years & 173 & $153(88.4)$ & $20(11.6)$ & \\
\hline \multicolumn{5}{|l|}{ I. Socioeconomic factors } \\
\hline \multicolumn{5}{|l|}{ Father's education } \\
\hline Low level (high school or less) & 380 & $368(96.8)$ & $12(3.2)$ & \multirow[t]{2}{*}{$<0.0001$} \\
\hline High level (college or university) & 198 & $112(56.6)$ & $86(43.4)$ & \\
\hline \multicolumn{5}{|l|}{ Mother's education } \\
\hline Low level (high school or less) & 427 & $405(94.8)$ & $22(5.2)$ & \multirow[t]{2}{*}{$<0.0001$} \\
\hline High level (college or university) & 151 & $75(49.7)$ & $76(50.3)$ & \\
\hline \multicolumn{5}{|l|}{ Parent's occupation } \\
\hline Health care provider & 30 & $2(6.7)$ & $28(93.3)$ & \multirow[t]{2}{*}{$<0.0001$} \\
\hline Other occupations & 548 & $478(87.2)$ & $70(12.8)$ & \\
\hline \multicolumn{5}{|l|}{ Family monthly income } \\
\hline Low $(\leq 10,000 S R)$ & 345 & $341(98.8)$ & $4(1.2)$ & \multirow[t]{2}{*}{$<0.0001$} \\
\hline High (> 10,000SR) & 233 & $139(59.7)$ & $94(40.3)$ & \\
\hline \multicolumn{5}{|l|}{ Region of residence } \\
\hline North Riyadh & 79 & $44(55.7)$ & $35(44.3)$ & \multirow[t]{5}{*}{$<0.0001$} \\
\hline South Riyadh & 114 & $106(93.0)$ & $8(7.0)$ & \\
\hline East Riyadh & 200 & $180(90.0)$ & $20(10.0)$ & \\
\hline West Riyadh & 108 & $83(76.9)$ & $25(23.1)$ & \\
\hline Central Riyadh & 77 & $67(87.0)$ & $10(13.0)$ & \\
\hline \multicolumn{5}{|l|}{ Type of residence } \\
\hline Rental home & 482 & $446(92.5)$ & $36(7.5)$ & \multirow[t]{2}{*}{$<0.0001$} \\
\hline Own home & 96 & $34(35.4)$ & $62(64.6)$ & \\
\hline \multicolumn{5}{|c|}{ Medical insurance with dental coverage } \\
\hline No & 447 & $423(94.6)$ & $24(5.4)$ & \multirow[t]{2}{*}{$<0.0001$} \\
\hline Yes & 131 & $57(43.5)$ & $74(56.5)$ & \\
\hline \multicolumn{5}{|l|}{ II. Child oral health behavior and practices } \\
\hline \multicolumn{5}{|l|}{ Frequency of brushing teeth per day } \\
\hline Less than once daily & 320 & $318(99.4)$ & $2(0.7)$ & \multirow[t]{3}{*}{$<0.0001$} \\
\hline Once daily & 128 & $100(78.1)$ & $28(21.9)$ & \\
\hline Two times or more daily & 130 & $62(47.7)$ & $68(52.3)$ & \\
\hline \multicolumn{5}{|l|}{ Started brushing teeth at the age } \\
\hline 2 years or less & 50 & $22(44.0)$ & $28(56.0)$ & $<0.0001$ \\
\hline 3 years & 82 & $46(56.1)$ & $36(43.9)$ & \\
\hline 4 years & 59 & $47(79.7)$ & $12(20.3)$ & \\
\hline $5-6$ years & 333 & $315(94.6)$ & $18(5.4)$ & \\
\hline Unknown & 54 & $50(92.6)$ & $4(7.4)$ & \\
\hline Dental floss use & & & & \\
\hline No & 568 & $472(83.1)$ & $96(16.9)$ & $0.6806+$ \\
\hline
\end{tabular}


Table 1 Distribution of various characteristics of study population and the relationship with caries status (Continued)

\begin{tabular}{|c|c|c|c|c|}
\hline \multirow[t]{2}{*}{ Characteristic } & \multirow{2}{*}{$\begin{array}{l}\text { All subjects } \\
(n=578)\end{array}$} & \multicolumn{2}{|l|}{ Caries status } & \multirow[t]{2}{*}{$p$ value ${ }^{*}$} \\
\hline & & Yes $(n=480)$ & No $(n=98)$ & \\
\hline Yes & 10 & $8(80.0)$ & $2(20.0)$ & \\
\hline \multicolumn{5}{|l|}{ Mouthwash use } \\
\hline No & 553 & $466(84.3)$ & $87(15.7)$ & \multirow[t]{2}{*}{$0.0011+$} \\
\hline Yes & 25 & $14(56.0)$ & $11(44.0)$ & \\
\hline \multicolumn{5}{|c|}{ Frequency of fluoride application } \\
\hline None & 454 & $414(91.2)$ & $40(8.8)$ & \multirow[t]{4}{*}{$<0.0001$} \\
\hline Every 6 months & 42 & $18(42.9)$ & $24(57.1)$ & \\
\hline Every 1 year & 38 & $8(21.1)$ & $30(78.9)$ & \\
\hline Unknown & 44 & $40(90.9)$ & $4(9.1)$ & \\
\hline \multicolumn{5}{|l|}{ Recent visit to dentist } \\
\hline Did not visit or unknown & 99 & $71(71.7)$ & $28(28.3)$ & \multirow[t]{3}{*}{$<0.0001$} \\
\hline$>1$ year & 214 & $208(97.2)$ & $6(2.8)$ & \\
\hline$\leq 1$ year & 265 & $201(75.8)$ & $64(24.2)$ & \\
\hline \multicolumn{5}{|l|}{ Reason for recent dental visit } \\
\hline Did not visit or unknown & 93 & $67(72.0)$ & $26(28.0)$ & \multirow[t]{3}{*}{$<0.0001$} \\
\hline Toothache & 363 & $357(98.3)$ & $6(1.7)$ & \\
\hline Checkup or consultation & 122 & $56(45.9)$ & $66(54.1)$ & \\
\hline \multicolumn{5}{|c|}{ Child ate after brushing teeth in the night } \\
\hline No & 221 & $133(60.2)$ & $88(39.8)$ & \multirow[t]{2}{*}{$<0.0001$} \\
\hline Yes & 357 & $347(97.2)$ & $10(2.8)$ & \\
\hline \multicolumn{5}{|l|}{ III. Child feeding practices } \\
\hline \multicolumn{5}{|l|}{ Type of milk feeding practice } \\
\hline Breast-fed only & 29 & $27(93.1)$ & $2(6.9)$ & \multirow[t]{3}{*}{0.0163} \\
\hline Mixed-fed & 487 & $395(81.1)$ & $92(18.9)$ & \\
\hline Powdered milk only & 62 & $58(93.6)$ & $4(6.5)$ & \\
\hline \multicolumn{5}{|c|}{ Age of the child when breast feeding was stopped } \\
\hline$\leq 1$ year & 409 & $361(88.3)$ & $48(11.7)$ & \multirow[t]{2}{*}{$<0.0001$} \\
\hline$>1$ year & 169 & $119(70.4)$ & $50(29.6)$ & \\
\hline \multicolumn{5}{|c|}{ Age of the child when drinking with a bottle was stopped } \\
\hline$\leq 1$ year & 50 & $44(88.0)$ & $6(12.0)$ & \multirow[t]{2}{*}{0.3286} \\
\hline$>1$ year & 528 & $436(82.6)$ & $92(17.4)$ & \\
\hline \multicolumn{5}{|c|}{ Child sleeps with bottle in mouth } \\
\hline No & 154 & $72(46.8)$ & $82(53.2)$ & \multirow[t]{2}{*}{$<0.0001$} \\
\hline Yes & 424 & $408(96.2)$ & $16(3.8)$ & \\
\hline \multicolumn{5}{|l|}{ Number of meals per day } \\
\hline $1-2$ meals & 47 & $42(89.4)$ & $5(10.6)$ & \multirow[t]{2}{*}{0.2286} \\
\hline 3 or more meals & 531 & $438(82.5)$ & $93(17.5)$ & \\
\hline Number of snacks consumed & & & & \\
\hline One snack & 156 & $78(50.0)$ & $78(50.0)$ & $<0.0001$ \\
\hline 2 or more snacks & 422 & $402(95.3)$ & $20(4.7)$ & \\
\hline Snack time corresponding to & & & & \\
\hline With main meals only & 80 & $26(32.5)$ & $54(67.5)$ & $<0.0001$ \\
\hline
\end{tabular}


Table 1 Distribution of various characteristics of study population and the relationship with caries status (Continued)

\begin{tabular}{|c|c|c|c|c|}
\hline \multirow[t]{2}{*}{ Characteristic } & \multirow{2}{*}{$\begin{array}{l}\text { All subjects } \\
(n=578)\end{array}$} & \multicolumn{2}{|l|}{ Caries status } & \multirow[t]{2}{*}{$p$ value } \\
\hline & & Yes $(n=480)$ & No $(n=98)$ & \\
\hline Between or with main meals & 390 & $370(94.9)$ & $20(5.1)$ & \\
\hline Unknown & 108 & $84(77.8)$ & $24(22.2)$ & \\
\hline \multicolumn{5}{|c|}{ IV. Dietary factors (consumed at least twice a week) } \\
\hline \multicolumn{5}{|l|}{ Multivitamin supplementation } \\
\hline No & 532 & $446(83.8)$ & $86(16.2)$ & 0.0853 \\
\hline Yes & 46 & $34(73.9)$ & $12(26.1)$ & \\
\hline \multicolumn{5}{|l|}{ Fresh fruits } \\
\hline No & 408 & $390(95.6)$ & $18(4.4)$ & $<0.0001$ \\
\hline Yes & 170 & $90(52.9)$ & $80(47.1)$ & \\
\hline \multicolumn{5}{|l|}{ Fresh vegetables or salads } \\
\hline No & 137 & $127(92.7)$ & $10(7.3)$ & 0.0006 \\
\hline Yes & 441 & $353(80.0)$ & $88(20.0)$ & \\
\hline \multicolumn{5}{|l|}{ Fast food } \\
\hline No & 235 & $157(66.8)$ & $78(33.2)$ & $<0.0001$ \\
\hline Yes & 343 & $323(94.2)$ & $20(5.8)$ & \\
\hline \multicolumn{5}{|l|}{ Candy } \\
\hline No & 96 & $60(62.5)$ & $36(37.5)$ & $<0.0001$ \\
\hline Yes & 482 & $420(87.1)$ & $62(12.9)$ & \\
\hline \multicolumn{5}{|l|}{ Potato chips } \\
\hline No & 96 & $64(66.7)$ & $32(33.3)$ & $<0.0001$ \\
\hline Yes & 482 & $416(86.3)$ & $66(13.7)$ & \\
\hline \multicolumn{5}{|l|}{ Sweetened chewing gum } \\
\hline No & 467 & $379(81.2)$ & $88(18.8)$ & 0.0131 \\
\hline Yes & 111 & $101(91.0)$ & $10(9.0)$ & \\
\hline \multicolumn{5}{|l|}{ Fresh juice } \\
\hline No & 394 & $370(93.9)$ & $24(6.1)$ & $<0.0001$ \\
\hline Yes & 184 & $110(59.8)$ & $74(40.2)$ & \\
\hline \multicolumn{5}{|l|}{ Flavored juices } \\
\hline No & 58 & $44(75.9)$ & $14(24.1)$ & 0.1243 \\
\hline Yes & 520 & $436(83.8)$ & $84(16.2)$ & \\
\hline \multicolumn{5}{|l|}{ Soft drinks } \\
\hline No & 183 & $105(57.4)$ & $78(42.6)$ & $<0.0001$ \\
\hline Yes & 395 & $375(94.9)$ & $20(5.1)$ & \\
\hline \multicolumn{5}{|l|}{ Fresh milk } \\
\hline No & 244 & $220(90.2)$ & $24(9.8)$ & $<0.0001$ \\
\hline Yes & 334 & $260(77.8)$ & $74(22.2)$ & \\
\hline \multicolumn{5}{|l|}{ Flavored milk } \\
\hline No & 372 & $294(79.0)$ & 78 (21.0) & 0.0006 \\
\hline Yes & 206 & $186(90.3)$ & $20(9.7)$ & \\
\hline
\end{tabular}


Table 2 Summary of variables selected in four main risk domains, encompassing socioeconomic factors, child oral health behavior and practices, child feeding practices, and dietary factors, at different steps of model selection process using logistic regression (LR) analysis*

\begin{tabular}{|c|c|c|c|}
\hline All variables & $\begin{array}{l}\text { Step } 1 \text { univariate } L R \\
\text { within risk domain }\end{array}$ & $\begin{array}{l}\text { Step } 2 \text { multivariate LR } \\
\text { within risk domain }\end{array}$ & $\begin{array}{l}\text { Final step multivariate } \\
\text { LR all } 4 \text { risk domains }\end{array}$ \\
\hline \multicolumn{4}{|l|}{ I. Socioeconomic factors } \\
\hline Father's education & $x$ & - & - \\
\hline Mother's education & $x$ & $x$ & $x$ \\
\hline Parent's occupation & $x$ & $x$ & - \\
\hline Family monthly income & $x$ & $x$ & $x$ \\
\hline Region of residence & $x$ & $x$ & - \\
\hline Type of residence & $x$ & - & - \\
\hline Medical insurance with dental coverage & $x$ & $x$ & $x$ \\
\hline \multicolumn{4}{|l|}{ II. Child oral health behavior and practices } \\
\hline Frequency of brushing teeth per day & $x$ & $x$ & $x$ \\
\hline Started brushing teeth at the age & $x$ & $x$ & $x$ \\
\hline Dental floss use & - & - & - \\
\hline Mouthwash use & $x$ & - & - \\
\hline Frequency of fluoride application & $x$ & $x$ & - \\
\hline Recent visit to dentist & $x$ & - & - \\
\hline Reason for recent dental visit & $x$ & $x$ & $x$ \\
\hline Child ate after brushing teeth in the night & $x$ & - & - \\
\hline \multicolumn{4}{|l|}{ III. Child feeding practices } \\
\hline Type of milk feeding practice & $x$ & $x$ & $x$ \\
\hline Age of the child when breast feeding was stopped & $x$ & $x$ & $\dagger$ \\
\hline Age of the child when drinking with a bottle was stopped & - & - & - \\
\hline Child sleeps with bottle in mouth & $x$ & $x$ & $x$ \\
\hline Number of meals per day & - & - & - \\
\hline Number of snacks consumed between meals & $x$ & $x$ & $x$ \\
\hline Snack time corresponding to main meals & $x$ & $x$ & - \\
\hline \multicolumn{4}{|l|}{ IV. Dietary factors (consumed at least twice a week) } \\
\hline Multivitamin supplementation & - & - & - \\
\hline Fresh fruits & $x$ & $x$ & $x$ \\
\hline Fresh vegetables or salads & $x$ & - & - \\
\hline Fast food & $x$ & - & - \\
\hline Candy & $x$ & - & - \\
\hline Potato chips & $x$ & - & - \\
\hline Sweetened chewing gum & $x$ & - & - \\
\hline Fresh juice & $x$ & $x$ & - \\
\hline Flavored juices & - & - & - \\
\hline Soft drinks & $x$ & $x$ & $x$ \\
\hline Fresh milk & $x$ & - & - \\
\hline Flavored milk & $x$ & $x$ & $x$ \\
\hline
\end{tabular}

*The variables selected in the step were marked with an " $\mathrm{X}$," and variable excluded is marked as "-." The variables selected were significant at $p$ value less than or equal to 0.05

†The variable "Age of the child when breast feeding was stopped" was excluded to address the issue of collinearity in the final model 
Table 3 Unadjusted odds ratios (uOR), adjusted odds ratios (aOR), and their respective 95\% confidence intervals (95\% Cl) of the key associated factors for dental caries in primary school children aged 6-8 years

\begin{tabular}{|c|c|c|c|c|}
\hline \multirow[t]{2}{*}{ Characteristic } & \multicolumn{2}{|c|}{ Unadjusted odds ratio } & \multicolumn{2}{|c|}{ Adjusted odds ratio* } \\
\hline & UOR & $95 \% \mathrm{Cl}$ & $\mathrm{aOR}$ & $95 \% \mathrm{Cl}$ \\
\hline \multicolumn{5}{|l|}{ I. Socioeconomic factors } \\
\hline \multicolumn{5}{|l|}{ Mother's education } \\
\hline Low level (high school or less) & 18.7 & $10.9-31.8$ & 4.4 & $1.3-15.5$ \\
\hline High level (college or university) & 1.0 & (Ref)† & 1.0 & (Ref)† \\
\hline \multicolumn{5}{|l|}{ Family monthly income } \\
\hline $\operatorname{Low}(\leq 10,000 \mathrm{SR})$ & 57.6 & $20.8-159.7$ & 28.2 & $5.2-153.9$ \\
\hline High (> 10,000SR) & 1.0 & (Ref) $\dagger$ & 1.0 & (Ref) $\dagger$ \\
\hline \multicolumn{5}{|c|}{ Medical insurance with dental coverage } \\
\hline No & 22.9 & $13.4-39.2$ & 4.2 & $1.2-14.3$ \\
\hline Yes & 1.0 & $(\operatorname{Ref})+$ & 1.0 & (Ref) $\dagger$ \\
\hline \multicolumn{5}{|l|}{ II. Child oral health behavior and practices } \\
\hline \multicolumn{5}{|l|}{ Frequency of brushing teeth per day } \\
\hline Less than once daily & 174.4 & $41.6-730.3$ & 30.1 & $3.1-294.3$ \\
\hline Once daily & 3.9 & $2.3-6.7$ & 0.2 & $0.0-0.6$ \\
\hline Two times or more daily & 1.0 & (Ref)† & 1.0 & (Ref)† \\
\hline \multicolumn{5}{|l|}{ Started brushing teeth at the age } \\
\hline 2 years or less & 1.0 & (Ref)† & 1.0 & (Ref) $\dagger$ \\
\hline 3 years & 1.6 & $0.8-3.3$ & 21.2 & $2.2-203.6$ \\
\hline 4 years & 5.0 & $2.1-11.6$ & 9.3 & $1.3-68.0$ \\
\hline $5-6$ years & 22.3 & $10.7-46.4$ & 1.7 & $0.3-9.6$ \\
\hline Unknown & 15.9 & $5.0-50.8$ & 0.1 & $0.0-1.3$ \\
\hline \multicolumn{5}{|l|}{ Reason for recent dental visit } \\
\hline Did not visit or unknown & 3.0 & $1.7-5.4$ & 0.1 & $0.0-0.6$ \\
\hline Toothache & 70.1 & $29.0-169.4$ & 21.4 & $3.9-119.3$ \\
\hline Checkup or consultation & 1.0 & $(\operatorname{Ref}) \dagger$ & 1.0 & (Ref) $\dagger$ \\
\hline \multicolumn{5}{|l|}{ III. Child feeding practices } \\
\hline \multicolumn{5}{|l|}{ Type of milk feeding practice } \\
\hline Breast-fed only & 3.1 & $0.7-13.5$ & 33.1 & $4.7-231.4$ \\
\hline Mixed-fed & 1.0 & (Ref)† & 1.0 & (Ref) $\dagger$ \\
\hline Powdered milk only & 3.4 & $1.2-9.5$ & 38.4 & $3.2-459.9$ \\
\hline \multicolumn{5}{|l|}{ Child sleeps with bottle in mouth } \\
\hline No & 1.0 & (Ref) $\dagger$ & 1.0 & (Ref) $\dagger$ \\
\hline Yes & 29.0 & $16.1-52.5$ & 4.4 & $1.4-13.4$ \\
\hline \multicolumn{5}{|c|}{ Number of snacks consumed between meals } \\
\hline One snack & 1.0 & (Ref) + & 1.0 & (Ref)† \\
\hline 2 or more snacks & 20.1 & $11.6-34.8$ & 6.8 & $2.1-21.4$ \\
\hline \multicolumn{5}{|c|}{ IV. Dietary factors (consumed at least twice a week) } \\
\hline \multicolumn{5}{|l|}{ Fresh fruits } \\
\hline No & 19.3 & 11.0-33.7 & 11.6 & $2.8-48.2$ \\
\hline Yes & 1.0 & (Ref)† & 1.0 & (Ref) $\dagger$ \\
\hline \multicolumn{5}{|l|}{ Soft drinks } \\
\hline No & 1.0 & $(\operatorname{Ref}) \dagger$ & 1.0 & $(\operatorname{Ref}) \dagger$ \\
\hline
\end{tabular}


Table 3 Unadjusted odds ratios (uOR), adjusted odds ratios (aOR), and their respective 95\% confidence intervals (95\% Cl) of the key associated factors for dental caries in primary school children aged 6-8 years (Continued)

\begin{tabular}{|c|c|c|c|c|}
\hline \multirow[t]{2}{*}{ Characteristic } & \multicolumn{2}{|c|}{ Unadjusted odds ratio } & \multicolumn{2}{|c|}{ Adjusted odds ratio* } \\
\hline & uOR & $95 \% \mathrm{Cl}$ & $\mathrm{aOR}$ & $95 \% \mathrm{Cl}$ \\
\hline Yes & 13.9 & $8.1-23.8$ & 5.3 & $1.5-18.0$ \\
\hline \multicolumn{5}{|c|}{ Flavored milk } \\
\hline No & 1.0 & (Ref) $\dagger$ & 1.0 & (Ref)† \\
\hline Yes & 2.5 & $1.5-4.2$ & 7.7 & $2.6-23.0$ \\
\hline
\end{tabular}

*Key associated factors for dental caries selected using stepwise multivariate logistic regression model in the final step of model selection process were included in the final model, and Firth's bias correction was applied

tReference category for the variable

influence of individual factors on dental caries' experience in children.

\section{Discussion}

Dental caries was prevalent among 6- to 8-year-old primary school children in Saudi Arabia $(83 \%, 95 \%$ CI 79.7-86.0). We identified individual factors, encompassing three major risk domains (children oral health behavior and practices, child feeding practices, and dietary habits) that were predominantly associated with dental caries' experience in our study. Especially, child oral health behavior and practices, such as brushing teeth at least once daily, starting the practice of brushing earlier than 2 years, and visiting a dentist regularly, were significantly associated with dental caries. In addition, children mixed-fed with both breast milk and powdered milk, children sleeping with bottle in mouth, and the practice of snacking two or more items between meals were linked to dental caries experience in children. Dietary habits, such as less frequent consumption of fresh fruits (once a week or less) and more frequent consumption of soft drinks and flavored milk (more than once a week), were significantly associated with dental caries in our study. In our sample, socioeconomic factors (less-educated mothers, low family income, and lack of dental insurance coverage) were less influential than individual factors in determining dental caries' experience in 6-8-year-old male primary school children.

The high prevalence of dental caries observed among primary school children in our sample was consistent with previous studies in Saudi Arabia [14, 21-24] and UAE [25]. A recent meta-analysis of various dental caries studies in different regions of Saudi Arabia determined the prevalence to be $80 \%$ [2]. Furthermore, the observed prevalence of dental caries among children in the present study was substantially higher than the target established for the year $2000(50 \%)$ by WHO/FDI [26]. The collective evidence from our study and previous studies confirm the endemic nature of dental caries in Middle Eastern population and signify the burden on public health.
It is interesting to note that dental caries' experience among primary school children was better explained by individual factors $(80 \%)$ rather than socioeconomic factors $(59 \%)$ in our study, which is consistent with weaker role of socioeconomic factors observed in developed nations $[6,15]$. This notion was further supported by the relatively stronger associations observed between individual factors and dental caries experience in our study. In contrast, several cross-sectional and longitudinal studies from developing nations demonstrated the dominant role of socioeconomic factors in dental caries' experience [18, 27-29]. The risk profile of dental caries among children in Saudi Arabia appears to follow the theme in developed world, where oral health behavioral practices and dietary habits were relatively more important [30]. However, efforts directed at improving socioeconomic status should be continued, owing to evidence from the present study and prior studies that identified maternal education and family income as consistent associated factors for dental caries [16, 17, 27, 28]. In addition, the availability of dental coverage in medical insurance was associated with dental caries. Although literary evidence was inconsistent in Saudi Arabia [16], the alarming proportion of children (77\%) that lacked dental coverage in medical insurance warrant further attention.

Our results were consistent with previous studies on dental caries that reported an association between dental caries and good oral health behaviors in general [10, 19], and tooth brushing habits in particular [31, 32]. A recent meta-analysis identified a 1.5-fold higher risk of dental caries among people brushing less than once daily compared to those brushing regularly (odds ratio $(\mathrm{OR})=1.56$; 95\% CI 1.37-1.78) [33]. An overwhelming majority of children started brushing after 2 years $(82 \%$, 95\% CI 78.6-85.1\%) in the present study, consistent with late adoption of brushing observed in previous studies in Saudi Arabia [20,34] and in Philippines [35]. However, the higher risk of dental caries observed uniquely among children who started brushing late at 3 or 4 years, in our sample, warrant further investigation. Particularly, future studies could evaluate the possible 
role of cultural habit of using chewing stick (Miswak) for cleaning teeth on better outcome observed among children starting brushing at ages 5-6 compared to those starting brushing at 3 or 4 years in Saudi Arabia. Given the importance of brushing teeth regularly and mouthwash use in maintaining good oral hygiene and preventing dental caries [10], and lower prevalence of these habits observed in our study, detailed investigation of various brushing practices (e.g., use of fluoridated/non fluoridated toothpaste, and use of chewing stick for cleaning teeth), and other oral hygiene practices (e.g., use of fluoride containing mouthwash) among primary school children in Saudi Arabia is necessary. Furthermore, interventions aimed at encouraging good oral health behaviors among children should be undertaken.

The negative attitude or apprehension towards visiting a dentist was clearly evident in our study, where only 21.1\% (95\% CI 17.8-24.7\%) of children visited a dentist for regular check-up, while the others visited for symptomatic treatment (e.g., toothache). The problem was even worse among younger children in Saudi Arabia; a mere $11 \%$ of children visited dentist for regular checkup on their first visit [20]. This dangerous trend might have prevented patients from availing sound advice on preventive oral health practices, thereby contributing to high prevalence, delayed recognition, and management of dental caries in Saudi Arabia. Therefore, Saudi children would benefit from publicly funded school-based dental screening programs that aid in timely detection and management of dental and other oral health problems. In addition, regular dental screening programs targeted at school children have an added benefit of realizing cost savings due to reduced need for advanced dental care [36].

The present study found a $4.5(\mathrm{OR}=4.5,95 \%$ CI $1.5-$ 13.8)-fold higher risk of dental caries among children falling asleep with the bottle in their mouth, which was consistent with literary evidence [37-39]. However, the magnitude of risk among Australian children sleeping with a bottle in mouth was much lower $(\mathrm{OR}=1.5,95 \%$ $\mathrm{CI}=1.1-2.2$ ) [39]. It was suggested that decreased salivary flow and reduced swallowing reflex as the child gets drowsier would allow carbohydrates to remain in the mouth and pool around the teeth priming the area for bacterial attack [40, 41].

The practice of frequently consuming sugary snacks between meals was associated with dental caries in our study. However, current evidence has been inconsistent with some studies indicating a positive association [42, 43], while others failed to observe such a relationship [44]. Therefore, further evaluation and confirmation of this globally relevant predictor is warranted.

Although breast feeding is commonly practiced in Western countries $[45,46]$, the practice of mixed feeding or partial breast feeding (with breast milk and powdered milk) was predominant in Saudi Arabia [47, 48]. Children in our study that were never breast-fed had higher risk of caries, which was consistent with existing literature [49-51]. Breast milk by itself was not cariogenic [52], but the reported cariogenicity of certain infant formulas [53] and a higher risk associated with practice of breast feeding until late infancy $(>12$ months - OR = 1.99; 95\% CI 1.35-2.95) [54] should not discourage the practice of mixed feeding until the emergence of new evidence. Interestingly, children in our study that were exclusively breast-fed also experienced higher risk of caries, rendering support to the practice of mixed feeding. As noted in previously published literature [54], it is possible that the practice of breast feeding until late infancy could have played a role in excess risk observed in Saudi children; however, further research based on a larger sample is warranted to confirm our findings and determine the role of duration of exclusive breast feeding on caries risk among children in Saudi Arabia.

Furthermore, our study identified that eating patterns and food choices play an important role in dental caries experience in children. Interestingly, the observed association between flavored milk and dental caries in this study could be a result of evolving trends in milk consumption practices in Saudi Arabia. Although prior observational studies $[55,56]$ contrast our findings, a moderate cariogenic potential of flavored milk observed in a recent animal experiment and the possibility of developing nations adopting this new trend warrant further evaluation [57]. Incidentally, our study contributed towards ever increasing evidence for the association between dental caries and sodas (or soft drinks) [58-60]. The acidic content of these soft drinks combined with sugars were known to reduce oral $\mathrm{pH}$ and increase the cariogenic potential of tooth [61].

It is noteworthy that low consumption of fresh fruits (less than twice a week) was associated with increased risk of dental caries among primary school children in this study. In contrast, the literary evidence did not provide a clear benefit of eating fresh fruits in preventing cariogenesis [62, 63]. However, certain fruit extracts (e.g., Morinda citrifolia) have been associated with inhibiting the growth of cariogenic bacteria [64], indicating the need to further evaluate the relevance of fresh fruit consumption to dental caries experience. In general, our findings were consistent with studies that linked intake of foods with high sugar content and dental caries in Saudi Arabia [19, 65] and other places [58-60, 66].

The strengths of this study are multi-fold. Information from various risk domains was systematically analyzed to aid in prioritizing the modifiable factors associated with dental caries experience in children. Unlike several prior studies in this area $[10,14,16,19,34]$, this study 
addressed the issue of multicollinearity and corrected potential bias from small sample in the analysis. The comprehensive nature of information collected encompassing various risk domains enabled us to evaluate the relative importance of individual factors over socioeconomic factors, a component seldom addressed in previous studies. Our study provides much needed baseline statistics on several population characteristics to aid not only local authorities, but also international organizations (e.g., WHO) to evaluate and improve the health programs aimed at mitigating the burden of dental caries in children.

However, certain limitations of this study should be considered while interpreting the results. A self-administered questionnaire was used as the main study instrument, which is subjected to recall bias. However, we do not expect our results to be grossly affected by recall, owing to recurrent and current themes tested in the questionnaire. For example, we would expect a more accurate recollection of tooth brushing habits and child feeding practices that were routine activities performed in the recent past; collection of information on flavored milk, a recent trend in Saudi Arabia, serves as an example for current themes. The study sample was restricted to 6-8-year-old male primary school children in Riyadh city of Saudi Arabia, which warrants caution in generalizing the results to the entire country; however, given the cultural homogeneity and urbanity of the area, we would expect our estimates to be relevant to general population. Our study does not support generalizing the results to girl children, as our sample was restricted to boys to comply with school regulations and cultural sensitivities of Saudi population. Although some of our findings could be relevant to girls owing to shared cultural practices, future research should evaluate and confirm gender-related differences. Moreover, the cross-sectional nature of this study warrants against drawing causal inferences.

\section{Conclusion}

The burden of dental caries is high in Saudi Arabia with eight out of ten primary school children aged 6-8 years suffering from this preventable condition. Several individual factors encompassing three risk domains, including oral health behaviors and practices, child feeding practices, and dietary habits, were found to be more relevant factors associated with dental caries than socioeconomic factors. Our results were consistent with findings in developed world where poor brushing habits, lack of dental coverage in health insurance, and high consumption of sodas were predominantly associated with dental caries. Future research should focus on confirming some of the unique or globally relevant associated factors for dental caries identified in our study, including late adoption of brushing, frequent consumption of sugary snacks between meals, and consumption of fresh fruits and flavored milk. Our results support the development and implementation of public awareness campaigns or health education programs targeted at primary school children to promote good oral health behaviors, feeding practices, and dietary habits.

\section{Additional file}

Additional file 1: Table S1. Unadjusted odds ratios (uOR), adjusted odds rations for variables selected within each risk domain (dOR), and adjusted odds ratios (aOR) for variables selected from all four risk domains at different steps of model selection process*. (DOCX $34 \mathrm{~kb}$ )

\section{Abbreviations}

95\% Cl: 95\% confidence interval; aOR: Adjusted odds ratio; dmft index: Decayed, missing and filled teeth index; FDI: Fédération Dentaire Internationale; MERS-cov: Middle East respiratory syndrome-corona virus; OR: Odds ratio; SD: Standard deviation; UOR: Unadjusted odds ratio; WHO: World Health Organization

\section{Acknowledgements}

We would like to thank the administration of the schools, parents, children and dental professionals who participated and provided assistance in our study. We also thank King Abdullah International Medical Research Center (KAIMRC) for partially funding our research.

\section{Funding}

King Abdullah International Medical Research Center (KAIMRC) partially funded our research (Grant number SP15/081). The funders had no role in the study design; collection, analysis, and interpretation of data; decision to publish; and preparation of the manuscript.

Availability of data and materials

Please contact the author for data requests.

Authors' contributions

$Y A$ and $H J$ conceived the project idea. $Y A, A A, N Y$, and $H J$ designed the study and approved the methodology. $Y A, A A$, and $H J$ participated in the data collection. YA, NY, and HJ managed the study data and conducted the formal data analysis. All authors contributed extensively towards the preparation of this manuscript and approved the version submitted to the journal. All authors read and approved the final manuscript.

Ethics approval and consent to participate

Ethics approval for this study, including oral examination of the children, was provided by the institutional review board (IRB) at King Abdullah International Medical Research Center (KAIMRC) in Riyadh under protocol number SP15/081. Informed consent was obtained from the parents.

Consent for publication

Not applicable.

\section{Competing interests}

The authors declare that they have no competing interests.

\section{Publisher's Note}

Springer Nature remains neutral with regard to jurisdictional claims in published maps and institutional affiliations.

\section{Author details}

${ }^{1}$ King Abdullah International Medical Research Center (KAIMRC), Riyadh, Saudi Arabia. ${ }^{2}$ Department of Epidemiology and Biostatistics, College of Public Health and Health Informatics, King Saud bin Abdulaziz University for Health Sciences, Mail Code 2350, P.O. Box 22490, Riyadh 11426, Saudi Arabia. ${ }^{3}$ King Abdulaziz Medical City for National Guard, Ministry of National Guard, Riyadh, Saudi Arabia. 
Received: 18 April 2018 Accepted: 30 October 2018 Published online: 30 November 2018

\section{References}

1. Vos T, Flaxman AD, Naghavi M, Lozano R, Michaud C, Ezzati M, et al. Years lived with disability (YLDs) for 1160 sequelae of 289 diseases and injuries 1990-2010: a systematic analysis for the Global Burden of Disease Study 2010. Lancet. 2012;380(9859):2163-96 https://doi.org/10.1016/s01406736(12)61729-2

2. Al Agili DE. A systematic review of population-based dental caries studies among children in Saudi Arabia. Saudi Dent J. 2013;25(1):3-11 https://doi. org/10.1016/j.sdentj.2012.10.002.

3. Petersen PE. The World Oral Health Report 2003: continuous improvement of oral health in the 21st century--the approach of the WHO Global Oral Health Programme. Community Dent Oral Epidemiol. 2003:31(Suppl 1):3-23.

4. Hobdell M, Petersen PE, Clarkson J, Johnson N. Global goals for oral health 2020. Int Dent J. 2003;53(5):285-8.

5. Gautam DK, Vikas J, Amrinder T, Rambhika T, Bhanu K. Evaluating dental awareness and periodontal health status in different socioeconomic groups in the population of Sundernagar, Himachal Pradesh, India. J Int Soc Prev Community Dent. 2012;2(2):53-7 https://doi.org/10.4103/2231-0762.109367.

6. Elani HW, Harper S, Allison PJ, Bedos C, Kaufman JS. Socio-economic inequalities and oral health in Canada and the United States. J Dent Res. 2012;91(9):865-70 https://doi.org/10.1177/0022034512455062.

7. Lasser KE, Himmelstein DU, Woolhandler S. Access to care, health status, and health disparities in the United States and Canada: results of a crossnational population-based survey. Am J Public Health. 2006;96(7):1300-7 https://doi.org/10.2105/ajph.2004.059402.

8. U.S. Department of Health and Human Services. Oral Health in America: A report of the Surgeon General. Rockville, MD: U.S. Department of Health and Human Services, National Institute of Dental and Craniofacial Research, National Institutes of Health; 2000.

9. Narang R, Mittal L, Jha K, Anamika R. Caries experience and its relationship with parent's education, occupation and socio economic status of the family among 3-6 years old preschool children of Sri Ganganagar City, India. Open journal of dentistry and Oral Medicine. 2013;1(1):1-4.

10. Amin TT, Al-Abad BM. Oral hygiene practices, dental knowledge, dietary habits and their relation to caries among male primary school children in $\mathrm{Al}$ Hassa, Saudi Arabia. Int J Dent Hyg. 2008;6(4):361-70 https://doi.org/10. 1111/j.1601-5037.2008.00310.x.

11. Woodward M, Walker AR. Sugar consumption and dental caries: evidence from 90 countries. Br Dent J. 1994;176(8):297-302.

12. De Pelsmaeker S, Schouteten J, Gellynck X. The consumption of flavored milk among a children population. The influence of beliefs and the association of brands with emotions. Appetite. 2013;71:279-86 https://doi. org/10.1016/j.appet.2013.08.016

13. World Health Organization. Oral health surveys: basic methods. 5th ed. Geneva: World Health Organization; 2013.

14. Farooqi FA, Khabeer A, Moheet IA, Khan SQ, Farooq I, ArRejaie AS. Prevalence of dental caries in primary and permanent teeth and its relation with tooth brushing habits among schoolchildren in Eastern Saudi Arabia. Saudi Med J. 2015:36(6):737-42 https://doi.org/10.15537/smj.2015.6.10888.

15. Reisine ST, Psoter W. Socioeconomic status and selected behavioral determinants as risk factors for dental caries. J Dent Educ. 2001;65(10): 1009-16.

16. Al Agili DE, Alaki SM. Can socioeconomic status indicators predict caries risk in schoolchildren in Saudi Arabia? A cross-sectional study. Oral Health Prev Dent. 2014;12(3):277-88.

17. Al-Meedani LA, Al-Dlaigan YH. Prevalence of dental caries and associated social risk factors among preschool children in Riyadh, Saudi Arabia. Pak J Med Sci. 2016:32(2):452-6.

18. Tagliaferro EPS, Ambrosano GMB, Meneghim MC, Pereira AC. Risk indicators and risk predictors of dental caries in schoolchildren. J Appl Oral Sci. 2008; 16(6):408-13.

19. Wyne AH, Khan N. Use of sweet snacks, soft drinks and fruit juices, tooth brushing and first dental visit in high DMFT 4-6 year olds of Riyadh region. Indian J Dent Res. 1995;6(1):21-4.

20. Wyne AH. Oral hygiene practices and first dental visit among early childhood caries children in Riyadh. Pakistan Oral \& Dent Jr. 2003;23(2):161-6.
21. Al-Shammery AR, Guile EE, Ei-Backly M. Prevalence of caries in primary school children in Saudi Arabia. Community Dent Oral Epidemiol. 1990; 18(6):320-1.

22. Wyne AH, Al-Ghorabi BM, Al-Asiri YA, Khan NB. Caries prevalence in Saudi primary school children of Riyadh and their teachers' oral health knowledge, attitude and practices. Saudi Med J. 2002;23(1):77-81.

23. Alamoudi N, Salako NO, Massoud I. Caries experience of children aged 6-9 years in Jeddah, Saudi Arabia. Int J Paediatr Dent. 1996;6(2):101-5.

24. Al-Malik MI, Rehbini YA. Prevalence of dental caries, severity, and pattern in age 6 to 7-year-old children in a selected community in Saudi Arabia. J Contemp Dent Pract. 2006;7(2):46-54.

25. Ai-Hosani E, Rugg-Gunn AJ. The relationship between diet and dental caries in 2 and 4 year old children in the Emirate of Abu Dhabi. Saudi Dent J. 2000;12:149-55.

26. Paul T, Maktabi A. Caries experience of 5-year-old children in Alkharj, Saudi Arabia. Int J Paediatr Dent. 1997;7(1):43-4

27. Peres MA, Peres KG, Traebert J, Zabot NE, Lacerda JT. Prevalence and severity of dental caries are associated with the worst socioeconomic conditions: a Brazilian cross-sectional study among 18-year-old males. J Adolesc Health. 2005;37(2):103-9 https://doi.org/10.1016/j.jadohealth. 2004.08.016.

28. Traebert J, Guimaraes Ldo A, Durante EZ, Serratine AC. Low maternal schooling and severity of dental caries in Brazilian preschool children. Oral health Prev Dent. 2009;7(1):39-45.

29. Rajab LD, Petersen PE, Baqain Z, Bakaeen G. Oral health status among 6and 12-year-old Jordanian schoolchildren. Oral health Prev Dent. 2014;12(2): 99-107.

30. Attaran N, Khoshnevisan MH, Ghorbani Z, Pakkhesal M, Dehghanian D. Dental caries predictors in countries with different human development index: a review of articles. Journal of International Oral Health. 2016:8(2): 182-90

31. Jensen O, Gabre P, Skold UM, Birkhed D. Fluoride toothpaste and toothbrushing; knowledge, attitudes and behaviour among Swedish adolescents and adults. Swed Dent J. 2011:35(4):203-13.

32. Smyth $\mathrm{E}$, Caamano F. Factors related to dental health in 12-year-old children: a cross-sectional study in pupils. Gac Sanit. 2005:19(2):113-9.

33. Kumar S, Tadakamadla J, Johnson NW. Effect of toothbrushing frequency on incidence and increment of dental caries: a systematic review and metaanalysis. J Dent Res. 2016;95(11):1230-6 https://doi.org/10.1177/ 0022034516655315

34. al Ghanim NA, Adenubi JO, Wyne AA, Khan NB. Caries prediction model in pre-school children in Riyadh, Saudi Arabia. Int J Paediatr Dent. 1998:8(2):115-22.

35. Carino KM, Shinada K, Kawaguchi Y. Early childhood caries in northern Philippines. Community Dent Oral Epidemiol. 2003;31(2):81-9.

36. World Health Organization. Oral health promotion: an essential element of a health-promoting school: World Health Organization; 2003. http://www. who.int/oral_health/media/en/orh_school_doc11.pdf. Accessed 16 Sep 2018

37. Nirunsittirat A, Pitiphat W, McKinney CM, DeRouen TA, Chansamak N, Angwaravong $\mathrm{O}$, et al. Breastfeeding duration and childhood caries: a cohort study. Caries Res. 2016;50(5):498-507.

38. Baginska J, Stokowska W. Dietary habits and early childhood caries intensity among young children. Wiad Lek. 2006:59(1-2):5-9.

39. Hallett KB, O'Rourke PK. Pattern and severity of early childhood caries. Community Dent Oral Epidemiol. 2006:34(1):25-35 https://doi.org/10.1111/j. 1600-0528.2006.00246.x

40. Seow WK. Biological mechanisms of early childhood caries. Community Dent Oral Epidemiol. 1998;26(1 Suppl):8-27.

41. Berkowitz RJ. Causes, treatment and prevention of early childhood caries: a microbiologic perspective. J Can Dent Assoc. 2003;69(5):304-7.

42. Iftikhar A, Zafar M, Kalar MU. The relationship between snacking habits and dental caries in school children. International Journal of Collaborative Research on Internal Medicine \& Public Health. 2012;4(12):1943-51.

43. Domejean-Orliaguet S, Gansky SA, Featherstone JD. Caries risk assessment in an educational environment. J Dent Educ. 2006;70(12):1346-54.

44. Punitha VC, Amudhan A, Sivaprakasam P, Rathanaprabu V. Role of dietary habits and diet in caries occurrence and severity among urban adolescent school children. J Pharm Bioallied Sci. 2015:7(Suppl 1):S296-300.

45. Gionet L. Breastfeeding trends in Canada. Canada: Statistics; 2015. http:// www.statcan.gc.ca/pub/82-624-x/2013001/article/11879-eng.htm. Accessed 10 Sep 2017 
46. Centers for Disease Control and Prevention. Breast feeding report card, United States 2014: Centers for Disease Control and Prevention; 2014. https://www.cdc.gov/breastfeeding/pdf/2014breastfeedingreportcard.pdf. Accessed 10 Sep 2017

47. Al-Nahedh NNA, Morley DC. Infant feeding practices and the decline of breast feeding in Saudi Arabia. Nutr Health. 1994;10(1):27-31.

48. Ogbeide DO, Siddiqui S, Al Khalifa IM, Karim A. Breast feeding in a Saudi Arabian community. Profile of parents and influencing factors. Saudi Med J. 2004;25(5):580-4.

49. Oulis CJ, Berdouses ED, Vadiakas G, Lygidakis NA. Feeding practices of Greek children with and without nursing caries. Pediatr Dent. 1999;21(7):409-16.

50. al-Dashti AA, Williams SA, Curzon ME. Breast feeding, bottle feeding and dental caries in Kuwait, a country with low-fluoride levels in the water supply. Community Dent Health. 1995;12(1):42-7.

51. Qadri G, Nourallah A, Splieth CH. Early childhood caries and feeding practices in kindergarten children. Quintessence Int. 2012;43(6):503-10

52. Erickson PR, Mazhari E. Investigation of the role of human breast milk in caries development. Pediatr Dent. 1999;21(2):86-90.

53. Peres RC, Coppi LC, Franco EM, Volpato MC, Groppo FC, Rosalen PL. Cariogenicity of different types of milk: an experimental study using animal model. Braz Dent J. 2002;13(1):27-32.

54. Tham R, Bowatte G, Dharmage SC, Tan DJ, Lau MX, Dai X, et al. Breastfeeding and the risk of dental caries: a systematic review and meta-analysis. Acta Paediatr. 2015;104(467):62-84 https://doi.org/10.1111/ apa.13118.

55. Dunning JM, Hodge AT. Influence of cocoa and sugar in milk on dental caries incidence. J Dent Res. 1971;50(4):854-9.

56. Levine RS. Milk, flavoured milk products and caries. Br Dent J. 2001;191(1):20.

57. Al-Jobair A, Khounganian R. Evaluating the cariogenic potential of flavored milk: an experimental study using rat model. J Contemp Dent Pract. 2015; 16(1):42-7.

58. Mariri BP, Levy SM, Warren JJ, Bergus GR, Marshall TA, Broffitt B. Medically administered antibiotics, dietary habits, fluoride intake and dental caries experience in the primary dentition. Community Dent Oral Epidemiol. 2003; 31(1):40-51.

59. Marshall TA, Levy SM, Broffitt B, Warren JJ, Eichenberger-Gilmore JM, Burns $T L$, et al. Dental caries and beverage consumption in young children. Pediatrics. 2003;112(3 Pt 1):e184-91.

60. Sohn W, Burt BA, Sowers MR. Carbonated soft drinks and dental caries in the primary dentition. J Dent Res. 2006;85(3):262-6 https://doi.org/10.1177/ 154405910608500311.

61. Cheng R, Yang H, Shao MY, Hu T, Zhou XD. Dental erosion and severe tooth decay related to soft drinks: a case report and literature review. J Zhejiang Univ Sci B. 2009;10(5):395-9.

62. Kleemola-Kujala E, Rasanen L. Dietary pattern of Finnish children with low high caries experience. Community Dent Oral Epidemiol. 1979;7(4):199-205.

63. Moynihan P, Petersen PE. Diet, nutrition and the prevention of dental diseases. Public Health Nutr. 2004;7(1a):201-26.

64. Kumarasamy B, Manipal S, Duraisamy P, Ahmed A, Mohanaganesh S, Jeevika C. Role of aqueous extract of Morinda citrifolia (Indian noni) ripe fruits in inhibiting dental caries-causing streptococcus mutans and streptococcus mitis. J Dent (Tehran). 2014;11(6):703-10.

65. Akpata ES, al-Shammery AR, Saeed HI. Dental caries, sugar consumption and restorative dental care in 12-13-year-old children in Riyadh, Saudi Arabia. Community Dent Oral Epidemiol. 1992;20(6):343-6.

66. Zhu L, Petersen PE, Wang HY, Bian JY, Zhang BX. Oral health knowledge, attitudes and behaviour of children and adolescents in China. Int Dent J. 2003;53(5):289-98.

\section{Ready to submit your research? Choose BMC and benefit from}

- fast, convenient online submission

- thorough peer review by experienced researchers in your field

- rapid publication on acceptance

- support for research data, including large and complex data types

- gold Open Access which fosters wider collaboration and increased citations

- maximum visibility for your research: over $100 \mathrm{M}$ website views per year

At BMC, research is always in progress.

Learn more biomedcentral.com/submissions 